\title{
Tuberculous lymphadenopathy in a dental patient: a review on clinical and diagnostic approach
}

\author{
Suwarna Dangore Khasbage* \\ Oral Medicine and Radiology, SharadPawar Dental College, DMIMSU, Wardha, India
}

\begin{abstract}
There is high incidence of tubercular cervical lymphadenitis in patients with enlarged neck nodes in developing countries like India. The clinical presentation of tubercular lymphadenitis mimics few other pathologic conditions that may result in misdiagnosis. Oral physician should be well versed about the clinical features of this condition in an attempt to formulate a differential diagnosis and to decide the appropriate treatment plan. Also, oral physician should always consider the possibility of tuberculous cervical lymphadenitis, if patient presents with neck swellings, especially of longer duration and not responding to routine antibiotics. A high index of suspicion can result in early diagnosis with the help of investigations and subsequently patients can be managed promptly without delay.
\end{abstract}

\section{Introduction}

Lymphadenopathy is one of the common finding in patients reporting to dental clinic. It is likely that over half of all patients examined each day may have enlarged lymph nodes in the head and neck region. Etiology of cervical lymphadenopathy is variable and thus the management also varies from patient to patient.

Cervical lymphadenopathy may be the only clinical finding or one of the several nonspecific findings, and the discovery of enlarged cervical lymph nodes will often raise the spectrum of major illness such as lymphoma, acquired immunodeficiency syndrome, metastatic cancer including tuberculosis. It is therefore imperative that oral physicians have to be well versed with the pathologies of cervical lymph nodes. The oral physicians's task is to efficiently differentiate the few patients with major illness from many with benign lymphadenopathy.

Tuberculosis is a granulomatous inflammatory process consequent to infection by Mycobacterium tuberculosis (human or bovine type). Tuberculosis affects $1 / 3 \mathrm{rd}$ of the world's population. Tubercular lymphadenitis is the commonest form of extra-pulmonary tuberculosis. Its incidence has started to rise worldwide in recent years, with the growing number of HIV-infected population [1].

\section{Case Report}

A 12-year-old girl reported to outpatient department of Oral Medicine and Radiology with complaint of painless swelling on left side of neck of approximately six to seven months duration. The patient was apparently alright seven months back, but she had noticed single small swelling on left side of neck. The swelling gradually increased in size and was painless. Her parents didn't give history of any systemic illness or history of blood transfusion to her in past. There was a history of occasional low-grade fever but no cough, anorexia or night sweats. No history of weight loss or difficulty in swallowing or breathing.

General examination revealed that the patient was in good health except the presence of single swelling on left side of neck. Thorough oral examination revealed no abnormality. On clinical examination single discrete swelling was present in posterior triangle of neck on left side. On palpation, the swelling was single mildly tender, firm, nodular and mobile with smooth intact overlying skin. Examination of contra lateral side was totally unremarkable. Lymphadenopathy due to nonspecific infection or specific infection like tuberculosis was considered in clinical differential diagnosis and the patient was considered for thorough evaluation by doing necessary investigations.

Results of her blood investigations were within normal limit. (hemoglobin $12 \mathrm{~g} / \mathrm{dl}$, White blood cell, $5.7 \times 10^{3}$ ul: Lymphocytes $38.1 \%$, monocytes $9.9 \%$, granulocytes $52 \%$. Chest X-ray showed clear lung fields; human immunodeficiency virus I \& II screening negative. To find out the exact reason for lymphadenopathy, fine needle aspiration was the only option. But, the patient's parents were not ready for any invasive procedure. She was treated by prescribing broad spectrum antibiotics for five days on empirical basis.

On follow up after five days, there was no change in the swelling. As a noninvasive investigation, ultrasonography of neck was performed which showed two enlarged, round $(\mathrm{S} / \mathrm{L}$ ratio $=0.57)$ matted lymph nodes with lost hilum in left posterior triangle of neck suggestive of tuberculous lymphadenopathy. Her ESR was raised and it was more than $30 \mathrm{~mm}$ in the first hour. Mantoux test was positive and was more than $15 \mathrm{~mm}$. Finally, the fine needle aspiration of the swelling was performed after taking informed consent of her parents. Aspiration report revealed presence of moderately good number of epithelioid cells, granulomas admixed with plenty of lymphoid cells with few scattered stromal fragments which was confirmatory of tuberculous lymphadenopathy. She was treated by anti tubercular therapy for 6 months and progress was assessed by clinical examination as well as by 3 monthly ESR estimation.

${ }^{\star}$ Correspondence to: Suwarna Dangore Khasbage, Sharad Pawar Dental College, Sawangi (M), Wardha, India, Fax: 07152-231412 E-mail: dangore_suwarna@ rediffmail.com

Key words: Cervical lymphadenitis, Tuberculous, Neck

Received: March 23, 2018; Accepted: April 16, 2018; Published: April 20, 2018 


\section{Discussion}

Tuberculosis is a worldwide infectious disease and constitutes second killer infectious disease after HIV despite advanced modalities for diagnosis and treatment [2]. Lymph node involvement is the most common presentation of extra pulmonary form of tuberculosis and cervical lymph nodes are the most commonly affected group of nodes. Amongst these the lymph nodes of the jugular chain, posterior triangle, and supraclavicular fossa are commonly involved [3].

An accurate diagnosis of tuberculous cervical lymphadenitis (TCL) has been a problem to clinicians because its clinical presentation often mimics few other diseases like lymphomas, local metastases of oral cancer, metastasis from other primary sites and certainly reactive lymphadenitis [4].

There are various methods for diagnosing the etiology and source of lymphadenopathy. Imaging today plays an important role in the evaluation of disease in the cervical lymph nodes. Obviously continuous advance of techniques leads to increasing sensitivity of the imaging modalities in the detection of lymph nodes.

Though aspiration cytology or histopathology confirm diagnosis, ultrasonography serves as a reliable, effective and non-invasive adjuvant in making the diagnosis. Ultrasound has advantages over other examination modalities in that it is noninvasive, inexpensive, time-saving, and able to guide procedures such as fine-needle aspiration and core-needle biopsy. It is increasingly being recognized as a primary tool for the evaluation of cervical lymph nodes.

Ultrasonography and computed tomography modalities are complementary in diagnosis and management of tuberculous lymphadenitis presenting with complications. Ultrasonography helps in better localization of site for biopsy/ or fine needle aspiration cytology and drainage of pus with high diagnostic yield. While computed tomography helps in better anatomical localization of lymph nodes not usually detected on clinical examination [5].

In cases of lymph nodes smaller than $0.5 \mathrm{~cm}$ the sensitivity of ultrasonography is superior than that of computed tomography and magnetic resonance imaging. Due to these facts and the availability of high frequency probes, ultrasonography become important in maxillofacial diagnosis [6].

Gupta et al. described ultrasound features of tuberculous lymphadenopathy in their study as hypoechogenecity in $100 \%$ cases, calcification in $29.6 \%$ cases, nodal matting in $37 \%$ cases and sharp border in $29.6 \%$ cases [5].

Das B et al.reported that there is very high incidence of tubercular cervical lymphadenitis in patients with enlarged neck nodes in developing countries like India. With improvement in economic, social conditions and the use of effective DOTS program, there is decline in pulmonary tuberculosis in developing countries but there is increase in incidence of extra-pulmonary form of tuberculosis [7].

The present case report as well as review suggests that when encountered with inflammatory cervical nodes, dentist should be alert about the possibility of tuberculous cervical lymphadenitis, one of the most common extrapulmonary tuberculoses.

\section{Conclusion}

Oral Physician should always consider the possibility of tuberculous cervical lymphadenitis if patient presents with neck swellings, especially of longer duration and not responding to routine antibiotics.

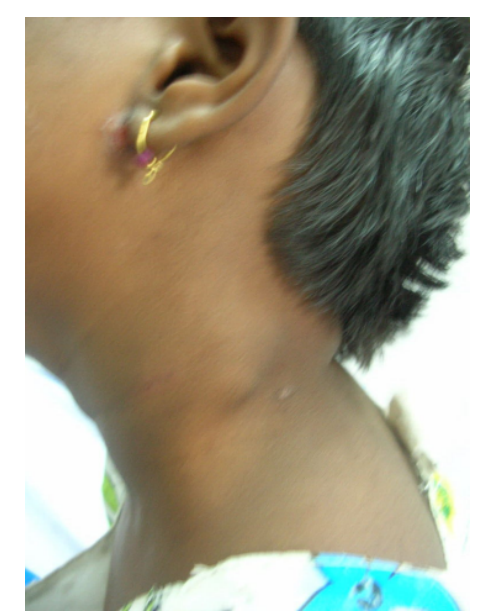

Figure 1. Enlarged lymph node in left posterior triangle

A high index of suspicion can result in early diagnosis with the help of investigations and subsequently patients can be managed promptly without delay.

\section{References}

1. Kazemnejad A, Arsang Jang S, Amani F, Omidi A et al. (2014) Global epidemic trend of tuberculosis during 1990e2010: using segmented regression model. J Res Health Sci 14: $115 \mathrm{e} 21$. [Crossref]

2. Sandhu GK (2011) Tuberculosis: Current Situation, Challenges and Overview of its Control Programs in India. J Glob Infect Dis 3: 143-150. [Crossref]

3. Marais BJ, Wright CA, Schaaf HS, Gie RP, Hesseling AC, et al. (2006) Tuberculous lymphadenitis as a cause of persistent cervical lymphadenopathy in children from a tuberculosis-endemic area. Pediatr Infect Dis J 25: 142e6. [Crossref]

4. Choi EC, Moon WJ, Lim YC (2009) Case report. Tuberculous cervical lymphadenitis mimicking metastatic lymph nodes from papillary thyroid carcinoma. Br J Radiol 82: e208-e211. [Crossref]

5. Gupta KB, Kumar A, Sen R (2007) Role of ultrasonography and computed tomography in complicated cases of tuberculous cervical lymphadenitis. Indian J Tuberc 54:71-78.

6. Chintamaneni R, Sudhakara M, Ravikiran A, Sathish S, Sujana B (2014) Evaluation of Reliability of Ultrasonographic Parameters in Differentiating Benign and Metastatic Cervical Group of Lymph Nodes. ISRN Otolaryngol 2014: 238740.

7. Das B, Basumatari S (2017) Incidence of tuberculosis in cervical lymphadenopathy. a clinico-epidemiological study. Int J Contemp Med Res 4: 1254-1257.

Copyright: (C2018 Khasbage SD. This is an open-access article distributed under the terms of the Creative Commons Attribution License, which permits unrestricted use, distribution, and reproduction in any medium, provided the original author and source are credited. 